\title{
Research on the Influencing Factors of the Willingness of New Professional Farmers to Participate in Skills Training and Its Promotion during the Development of Urban Modern Agriculture
}

\author{
Yixi Liu ${ }^{1,2}$, Pingyan Guo ${ }^{1}$, Zhiyao $\mathrm{Ma}^{2}$, Chun $\mathrm{Hu}^{3 *}$ \\ ${ }^{1}$ School of art and design, Zhejiang Tongji Vocational College of Science and Technology, Hangzhou, \\ Zhejiang, China \\ ${ }^{2}$ School of architecture, Tianjin University, Tianjin, Tianjin, China \\ ${ }^{3}$ School of landscape architecture and water conservancy engineering, Wenzhou Vocational College of \\ Science and Technology, Wenzhou, Zhejiang, China \\ *Corresponding author.
}

\begin{abstract}
Objective: Talent is the key factor in the implementation of the Rural Revitalization Strategy. Based on the willingness and influencing factors of new professional farmers to participate in skill training in the development of modern urban agriculture, this study seeks to study the education of professional farmers from the perspective of demand. Methods: Based on the questionnaire survey data of new vocational farmers in Wenzhou, this study systematically analyzed the current situation, training willingness, training methods, and training effect of new vocational training, and made quantitative statistical analysis of the original basic data. Combined with the characteristics of agricultural industry and post, this study empirically analyzed their perception of participating in skill training and the influencing factors. Results: The number of new vocational farmers willing to participate in training was significantly higher than that of farmers unwilling to participate in training. The frequency of technical problems encountered in agricultural production, the times of training, the evaluation of training effect, effect, cost, teacher level, hardware level, certificate, and other factors have a significant impact on the willingness of new vocational farmers to participate in skills training. Conclusion: This study proposes to build a vocational occupation education system to enhance the training intention of new occupation farmers. During the COVID-19, the innovative form of webcast sales realized the unification of technology and service.
\end{abstract}

Keywords: New professional farmers, skills training; training willingness, influencing factors, vocational education

\section{Introduction}

The problem of "Who Will Plant Land" and "Who Will Plant Good Land" has become an urgent problem to be solved in the development of modern agriculture, and also a key problem to be solved in the implementation of rural talent revitalization strategy. Modern urban agriculture has been put in a more important position. "We must vigorously develop occupation education and training, effectively enhance the skills and income level of labourers", and propose that new occupation farmers should "Love Agriculture, Understand the Technology and Operate Well". The development of modern urban agriculture relies on the innovation of technology, the diversification of business models, and the integration of multi production. However, at this stage, the agricultural business environment, income, welfare, and other factors such as "Aging", "Self-sufficiency" and "Low Efficiency" are increasingly losing market position, which seriously affects the sustainable development of modern urban agriculture. Throughout the No.1 central document, farmers' education was pointed out in 2004. From 2004, vocational skills training was accelerated, and new farmers were raised in 2007. In 2012, the new occupation farmers were vigorously nurturing. In 2016, the new training occupation farmers were basically trained to form a new occupation education system. In 2020, it is proposed to speed up the construction of a high-quality farmers' education and training systems. In the Fifth Plenary Session of the 19th CPC Central Committee, it was pointed out that "we should increase human capital

ISSN: 0010-8189

(C) CONVERTER 2021

www.converter-magazine.info 
investment and strengthen the cultivation of innovative, applied and skilled talents." Given this, based on the questionnaire survey and in-depth interview of the person in charge of Wenzhou Municipal demonstration cooperatives, this study systematically analyzed the current situation, training willingness, training methods and training effect of new vocational training, and made quantitative statistical analysis on the original basic data, combined with the characteristics of agricultural industry and post, based on the participation of new vocational farmers in the development of urban modern agriculture. This paper focuses on the willingness and influencing factors of skill training, and further discusses how to effectively use the willingness and influencing factors, to continuously improve the supply of Vocational and technical education, and seek to study the education problems of vocational farmers from the perspective of demand, to make them constantly adapt to the needs of social development in the development of vocational education, enhance the effectiveness of new vocational farmers' training, and put forward some suggestions to raise the level of vocational education has a certain practical significance.

\section{The Current Situation of Research}

In foreign countries, professional farmers have already completed the transformation of identity and technology, and presented a training mode suitable for their own country, highlighting the professionalization and institutionalization [1-3], which has a certain reference significance for the education of professional farmers in China. But at present, domestic research mainly focuses on the training and education of vocational farmers. Some scholars also pointed out some disadvantages of Vocational Agricultural training and put forward corresponding ideas and countermeasures [4-6], especially in the fields of agricultural science and technology progress [7], farmers' competency [8], education management system [9] and so on. Only in the land, agricultural organizations, government support, farmer education system to create a good endogenous environment [10], in order to accurately cultivate modern new professional farmers. At the same time, in the factors of new professional farmers' willingness to participate in training, experts use a variety of research methods to analyze and summarize, among which the individual characteristics of farmers [11], training supply and effect [12], government subsidies and policies [13] have more influence on the new professional farmers' willingness to participate in training, and the ability to obtain agricultural production factors [14], professional resilience and intergenerational transmission willingness [15] have become the key factors of their sustainable farming Key factors. New professional farmers have better basic conditions, profitability, knowledge level, etc. In the structural equation model of the influencing factors of training willingness, the degree of influence of training supply and effect is greater than that of farmers' personal characteristics [16], and training has a positive income effect and performance [17]. The difference in training effect and the heterogeneity of training demand are revealed [18]. In addition, other scholars have carried out specific training willingness factors research. Based on the research of Zhejiang Province [19], it is pointed out that gender, education level, years in industry, income level, and so on have a significant impact on the willingness of new vocational farmers to participate in training. In addition, further studies [20] in Wuhan, Xiamen, and Cangzhou found that income level and education level were positively correlated with farmers' vocational skills training willingness, but age, working years, and the number of cultivated land were negatively correlated with farmers' vocational skills training willingness. Income level and age become the most important factors. Among them, income level, education level, and age are consistent with the survey results of new professional farmers in Fujian Province [11], but there are differences in gender influence, which may be related to the economic development of the research subject. At the same time, income level and age also affect farmers' willingness to participate in entrepreneurship training [21], especially income level directly affects the evaluation of training satisfaction [22]. In the initial stage of training, government support policies, training methods and contents, policy publicity and so on also become the key factors affecting the training effect [23].

The characteristics of vocational education are mainly determined by its unique attributes. Although the relevant scholars mainly focus on the training mode, training mechanism, and training willingness of vocational farmers, there are many theoretical studies and a lack of typical empirical studies, so it is difficult to get a scientific and reasonable explanation from the objective phenomenon of characteristics. Therefore, based on the perspective of urban modern agricultural development, this study analyzes the willingness perception and influencing factors of

ISSN: 0010-8189

(C) CONVERTER 2021

www.converter-magazine.info 
typical new vocational farmers to participate in skill training. This study empirically analyzes the internal coupling relationship, the internal mechanism, and the original phenomenon. This study provides a relevant research basis for the follow-up vocational farmers' education and training will, and puts forward a new path for rural governance and agricultural development.

\section{Data Sources and Results}

\subsection{Data sources and survey overview}

The data used in this study are from September to November 2018. More than 230 questionnaires and in-depth interviews were sent out to the leaders of Wenzhou Municipal demonstration cooperatives, and 210 valid questionnaires were collected for the missing or contradictory key problems, with an effective recovery rate of $91.30 \%$. By the end of 2017, there were nearly 10000 farmers' professional cooperatives in Wenzhou, including 303 municipal demonstration farmers' cooperatives. This study selects farmers' professional cooperatives that are recognized by the municipal agricultural and rural department as a municipal demonstration organization with strong business strength and product quality and safety to conduct investigation and analysis. The annual operating service income is more than 2 million yuan, and the number of members is high. The average level of professional farmer cooperatives in the same industry in the local area, etc., are gathered around the towns, and there are more than 230 in total. They are the leaders of farmers' professional cooperatives of municipal demonstration organizations, with a high level of education, strong professional skills and management, and a certain industrial foundation. Their income mainly comes from the "Production and Management" new professional farmer leaders who have reached a high level in the promotion and demonstration of science and technology, agricultural scale output value, and management innovation mode. During the COVID-19 period, they could use the "Live Broadcast" innovation to carry out the sale of special agricultural products, achieving the unification of technology and service.

In addition, the survey data includes the basic information of new vocational farmers' skills needs and demonstration cooperatives, and the questionnaire involves the detailed information of farmers' individual characteristics and industrial situation, training status and effectiveness, training needs, and willingness. The summary and preliminary statistical results of the sample data are shown in Table 1.

Table 1 The main variables involved in the questionnaire survey, definition of variables, and preliminary statistical results

\begin{tabular}{|c|c|c|c|c|}
\hline \multirow[t]{2}{*}{ Variable name } & \multirow[t]{2}{*}{ Variable definition } & \multicolumn{2}{|c|}{$\begin{array}{c}\text { Sample number and } \\
\text { proportion of the variable } \\
\text { value }\end{array}$} & \multirow{2}{*}{$\begin{array}{c}\text { Sample } \\
\text { mean }\end{array}$} \\
\hline & & $\begin{array}{c}\text { Number of } \\
\text { samples }\end{array}$ & $\begin{array}{c}\text { Proportion } \\
/ \%\end{array}$ & \\
\hline \multirow{5}{*}{ Age } & Under 24 years old $=1$ & 0 & 0.00 & 3.76 \\
\hline & $25-34$ years old $=2$ & 14 & 6.80 & \\
\hline & $35-44$ years old $=3$ & 65 & 31.07 & \\
\hline & $45-54$ years old $=4$ & 86 & 40.78 & \\
\hline & Over 55 years old $=5$ & 45 & 21.36 & \\
\hline \multirow{2}{*}{ Gender } & Male $=1$ & 193 & 91.71 & - \\
\hline & Female $=2$ & 17 & 8.29 & \\
\hline \multirow{3}{*}{ degree of education } & Primary school and below $=1$ & 15 & 7.28 & 2.93 \\
\hline & Junior high school = 2 & 65 & 31.07 & \\
\hline & $\begin{array}{l}\text { Senior high school (technical } \\
\text { secondary school) }=3\end{array}$ & 66 & 31.55 & \\
\hline
\end{tabular}

ISSN: 0010-8189 


\begin{tabular}{|c|c|c|c|c|}
\hline & $\begin{array}{l}\text { Junior College (Higher } \\
\text { Vocational) }=4\end{array}$ & 54 & 25.73 & \\
\hline & Bachelor degree or above $=5$ & 9 & 4.37 & \\
\hline \multirow{8}{*}{ Planting industry } & Vegetable $=1$ & 41 & 19.52 & - \\
\hline & Fruit $=2$ & 73 & 34.76 & \\
\hline & Chinese herbal medicine $=3$ & 15 & 7.14 & \\
\hline & Animal husbandry $=4$ & 46 & 21.90 & \\
\hline & Agricultural products & 30 & & \\
\hline & processing $=5$ & 0 & 14.29 & \\
\hline & Leisure tourism $=6$ & 17 & 8.10 & \\
\hline & Others $=7$ & 52 & 24.76 & \\
\hline \multirow{5}{*}{$\begin{array}{l}\text { Years engaged in } \\
\text { the industry }\end{array}$} & Within 1 year $=1$ & 1 & 0.49 & 3.60 \\
\hline & $2-5$ years $=2$ & 18 & 8.37 & \\
\hline & $6-10$ years $=3$ & 83 & 39.41 & \\
\hline & $11-20$ years $=4$ & 73 & 34.98 & \\
\hline & More than 20 years $=5$ & 35 & 16.75 & \\
\hline \multirow{9}{*}{ Income level } & Less than $5000=1$ & 1 & 0.49 & - \\
\hline & $50-10000=2$ & 13 & 6.34 & \\
\hline & $20000-30000=3$ & 34 & 16.10 & \\
\hline & $40000-50000=4$ & 62 & 29.76 & \\
\hline & $60000-100000=5$ & 58 & 27.80 & \\
\hline & $110000-200000=6$ & 27 & 12.68 & \\
\hline & $210000-500000=7$ & 12 & 5.85 & \\
\hline & $51-1$ million $=8$ & 2 & 0.98 & \\
\hline & Over 1.01 million $=9$ & 0 & 0.00 & \\
\hline \multirow{4}{*}{$\begin{array}{l}\text { Proportion of } \\
\text { agricultural income }\end{array}$} & Below $40 \%=1$ & 22 & 10.19 & - \\
\hline & $40-59 \%=2$ & 33 & 15.69 & \\
\hline & $60-79 \%=3$ & 54 & 25.49 & \\
\hline & Over $80 \%=4$ & 102 & 48.53 & \\
\hline \multirow{4}{*}{$\begin{array}{l}\text { Frequency of } \\
\text { technical problems } \\
\text { encountered in } \\
\text { agricultural } \\
\text { production }\end{array}$} & No $=1$ & 7 & 3.45 & 1.96 \\
\hline & Few $=2$ & 34 & 16.26 & \\
\hline & General $=3$ & 56 & 26.60 & \\
\hline & Frequent $=4$ & 113 & 53.69 & \\
\hline \multirow{4}{*}{ Times of training } & 0Times $=1$ & 14 & 6.67 & 3.34 \\
\hline & 1 Times $=2$ & 31 & 14.76 & \\
\hline & 2 Times $=3$ & 39 & 18.57 & \\
\hline & 3Times and above $=4$ & 126 & 60.00 & \\
\hline \multirow{4}{*}{$\begin{array}{l}\text { Perception of } \\
\text { training needs }\end{array}$} & $\mathrm{No}=1$ & 7 & 3.45 & 1.97 \\
\hline & Few $=2$ & 34 & 16.26 & \\
\hline & General $=3$ & 56 & 26.60 & \\
\hline & Frequent $=4$ & 113 & 53.69 & \\
\hline \multirow{4}{*}{$\begin{array}{l}\text { Perception of the } \\
\text { role of training }\end{array}$} & No effect $=1$ & 8 & 3.90 & 1.86 \\
\hline & Little effect $=2$ & 29 & 13.66 & \\
\hline & Greater effect $=3$ & 100 & 47.80 & \\
\hline & Great effect $=4$ & 73 & 34.63 & \\
\hline \multirow{2}{*}{$\begin{array}{l}\text { Perception of } \\
\text { training effect }\end{array}$} & Very dissatisfied $=1$ & 4 & 1.96 & 2.03 \\
\hline & Not satisfied $=2$ & 8 & 3.92 & \\
\hline
\end{tabular}

ISSN: 0010-8189 


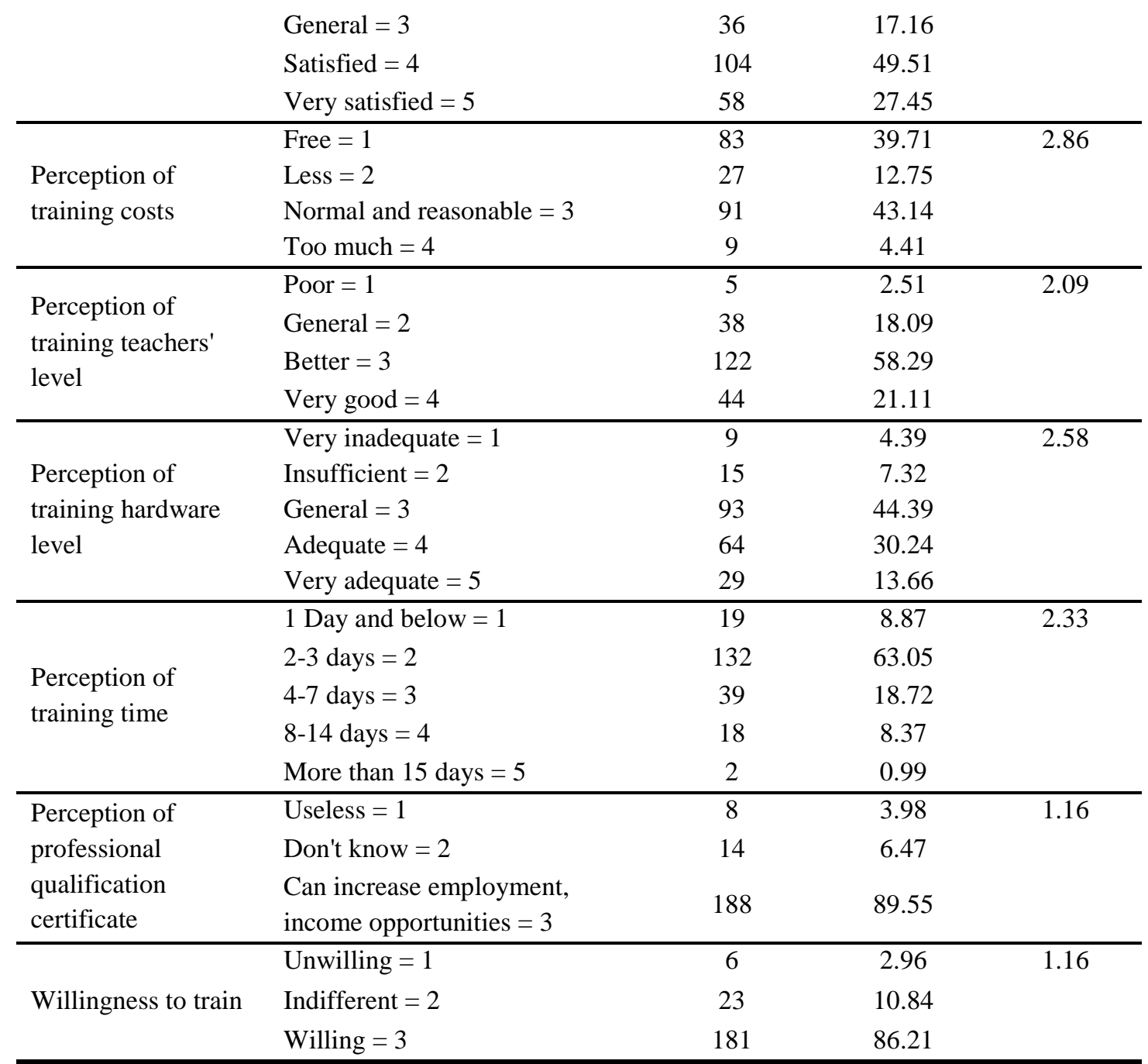

The data in Table 1 shows that the new professional farmers are characterized by independence, mobility and openness, intensification and specialization, and high quality. New professional farmers mainly grow fruits, vegetables, animal husbandry, agricultural products processing, leisure tourism, Chinese herbal medicine, etc., which are high value-added agricultural products. More than $50 \%$ of the new professional farmers often encounter technical problems in the production process, but their perception of skill training is quite different, which indicates that there may be other factors affecting farmers' training willingness. The statistical results of new vocational farmers' willingness to participate in training show that $86.21 \%$ of new vocational farmers are willing to participate in training, which is much higher than the proportion of farmers who are not willing to participate in training $(2.96 \%)$. This shows that although many factors affect the willingness to participate in training, the farmers' demand for training is still at a high level.

\subsection{Factors influencing training willingness and their correlation analysis}

In order to screen out the factors that can affect the willingness of new vocational farmers to participate in skills training. Based on the preliminary statistical analysis of the survey, this paper makes a quantitative analysis of the related influencing factors of farmers' willingness to participate in skills training. In this study, SPSS (16.0) was used to test the Pearson correlation of each factor, and the results are shown in Table 2.

From the data shown in Table 2, it can be seen that among the significant factors influencing the willingness of new

ISSN: 0010-8189 
vocational farmers to participate in skill training, the frequency of technical problems, the number of times to participate in training, the perception of training effect, the perception of training effect, the perception of the training cost, the perception of training teachers' level, the perception of training hardware level and the perception of training certificate are the most important the key.

In order to further confirm the influence of various factors that are significantly related to the new vocational farmers' participation in skill training on the training factors, this study uses SPSS (16.0) to carry out one-way ANOVA one by one to determine the significance of these factors. The results are shown in Table 3.

The results of one-way ANOVA showed that the frequency of technical problems encountered in agricultural production, the times of training, the evaluation of training effect, effect, cost, teacher level, hardware level, certificate, and other factors had a significant impact on the willingness of new vocational farmers to participate in skill training. The results were significantly correlated with the participation of new vocational farmers in skills training, and the analysis of variance results was significant. The results also show that these factors have a significant impact on the willingness of new vocational farmers to participate in skills training.

Table 2 Correlation analysis results of variables

\begin{tabular}{|c|c|c|}
\hline Variable name & $\begin{array}{c}\text { Correlation } \\
\text { coefficient }\end{array}$ & $\begin{array}{c}\text { Significance } \\
\text { level }\end{array}$ \\
\hline Gender & 0.129 & 0.062 \\
\hline Age & 0.029 & 0.681 \\
\hline Degree of education & 0.049 & 0.484 \\
\hline $\begin{array}{l}\text { Years engaged in the } \\
\text { industry }\end{array}$ & 0.097 & 0.162 \\
\hline Income level & 0.026 & 0.708 \\
\hline Income structure & 0.011 & 0.870 \\
\hline $\begin{array}{l}\text { Frequency of technical } \\
\text { problems encountered in } \\
\text { agricultural production }\end{array}$ & $0.205^{* *}$ & 0.003 \\
\hline Times of training & $-0.256^{* *}$ & $<0.001$ \\
\hline $\begin{array}{l}\text { Perception of the role of } \\
\text { training }\end{array}$ & $0.371 * *$ & $<0.001$ \\
\hline $\begin{array}{l}\text { Perception of training } \\
\text { effect }\end{array}$ & $0.476 * *$ & $<0.001$ \\
\hline $\begin{array}{l}\text { Perception of training } \\
\text { costs }\end{array}$ & $-0.232 * *$ & $<0.001$ \\
\hline $\begin{array}{l}\text { Perception of training } \\
\text { teachers' level }\end{array}$ & $0.485^{* *}$ & $<0.001$ \\
\hline $\begin{array}{l}\text { Perception of training } \\
\text { hardware level }\end{array}$ & $0.263 * *$ & $<0.001$ \\
\hline $\begin{array}{l}\text { Perception of training } \\
\text { time }\end{array}$ & 0.066 & 0.342 \\
\hline $\begin{array}{l}\text { Perception of training } \\
\text { certificate }\end{array}$ & $0.330 * *$ & $<0.001$ \\
\hline
\end{tabular}

Note: $* * *$, respectively indicate that the statistical test reaches the significance level of 5\% and $1 \%$.

Table 3 Results of one way ANOVA

ISSN: 0010-8189 


\begin{tabular}{|c|c|c|c|c|c|}
\hline Variable name & Freedom & F test value & $\begin{array}{l}\text { Inter- } \\
\text { group } \\
\text { variance }\end{array}$ & $\begin{array}{l}\text { Intragroup } \\
\text { variance }\end{array}$ & $\begin{array}{l}\text { Significance } \\
\text { level }\end{array}$ \\
\hline $\begin{array}{l}\text { Frequency of technical } \\
\text { problems encountered in } \\
\text { agricultural production }\end{array}$ & 210 & 6.103 & 3.305 & 37.190 & 0.001 \\
\hline Times of training & 210 & 5.093 & 2.796 & 37.699 & 0.002 \\
\hline $\begin{array}{l}\text { Perception of the role of } \\
\text { training }\end{array}$ & 210 & 17.314 & 8.155 & 32.341 & $<0.001$ \\
\hline $\begin{array}{l}\text { Perception of training } \\
\text { effect }\end{array}$ & 210 & 22.342 & 12.294 & 28.201 & $<0.001$ \\
\hline $\begin{array}{l}\text { Perception of training } \\
\text { costs }\end{array}$ & 210 & 6.963 & 3.728 & 36.767 & $<0.001$ \\
\hline $\begin{array}{l}\text { Perception of training } \\
\text { teachers' level }\end{array}$ & 210 & 26.923 & 13.947 & 26.549 & $<0.001$ \\
\hline $\begin{array}{l}\text { Perception of training } \\
\text { hardware level }\end{array}$ & 210 & 5.344 & 3.824 & 36.672 & $<0.001$ \\
\hline $\begin{array}{l}\text { Perception of training } \\
\text { certificate }\end{array}$ & 210 & 14.170 & 4.877 & 35.619 & $<0.001$ \\
\hline
\end{tabular}

\section{Data statistics results and evaluation analysis}

\subsection{Among the factors of personal characteristics}

Gender has no significant effect on training willingness, and the proportion of men engaged in agriculture is far greater than that of women. This shows that in the new professional farmers' group, men are more willing to accept new things and think more long-term because of their physical strength and social relations, which has a certain continuity with the traditional farming activities of men and women. This result is inconsistent with the conclusion that there is a positive correlation [11] and a negative correlation [20] between age and farmers' training willingness, and with the increase of age, training willingness will also show a "Convex" linear characteristics. Analysis of the reasons for this phenomenon, on the one hand, maybe because most of the new professional farmers are from the transformation of traditional agriculture, and they are mostly production and management experts. The new professional farmers tend to be the same in skills acquisition, learning path, and ability, while the younger new professional farmers are less engaged in agricultural production and management activities, or their education level has not improved. On the other hand, the current skills training for new vocational farmers is not universal, which is also one of the reasons that the age factor does not show a significant impact. Education level has no significant effect on the training willingness of new vocational farmers, but the improvement of education level becomes the driving force of technology promotion and innovation of new vocational farmers. The improvement of education level strongly promotes the application of learning and the transformation and utilization of scientific and technological achievements, which also urges them to participate in skill training more actively. At the same time, with the upgrading of new professional farmers' skills, it will bring reform and progress to the production and operation dominated by high-intensity labor at the present stage, promote and influence each other, and make new professional farmers more willing to participate in skills training.

\subsection{Among the related factors of production and operation}

The year of engaging in the industry, income level, and income structure have no significant impact on the willingness of training. This result is not consistent with the conclusion of relevant scholars. There is a correlation [19] and a negative correlation [20] between years of engaging in this industry and farmers' training willingness. At the same time, the income level and farmers' willingness to train are not consistent in the relevant conclusions. The relevant studies believe that there are correlation conclusions [11,19] and positive correlation [16,20] conclusions. For the reason of this phenomenon, on the one hand, it may be that the main body of this research is the person in charge of the municipal demonstration cooperatives, which has a certain industrial foundation, has certain advantages in agricultural output value, scientific and technological content, planting area and so on, and is generally engaged

ISSN: 0010-8189

(C) CONVERTER 2021

www.converter-magazine.info 
in agriculture for a long time, so it is not obvious for the training to change the existing situation. At the same time, the education level of new vocational farmers is high, the professional cooperatives they are in have high recognition in the field of the agricultural industry, the income is stable, and the training content is difficult to change the status quo, so the effect is not obvious, and it is difficult to guide production practice. On the other hand, the current skills training for new vocational farmers is not targeted, and the theory is divorced from practice, which may also be one of the reasons that the years of engaging in the industry, income level, and other factors do not show a significant impact. In addition, Wenzhou is famous for its landscape city, and its agriculture is mainly in mountainous areas, so it is unable to form a large-scale planting mode. The existing mechanization new technology is difficult to be popularized and applied in mountainous areas, and agriculture is a weak industry, its income accounts for the income of farmers is not obvious, the benefit is not obvious. The frequency of technical problems in agricultural production has a significant impact on training willingness, and farmers who encounter technical problems in production and management are more inclined to actively participate in skill training. This result is consistent with the viewpoint of human behavior science, that is, the motivation orientation and behavior mode are formed by the technological demand, the stimulation of human intrinsic motivation, and environment. In the process of production and operation, when encountering technical problems and causing production and operation risks in reality, they will subconsciously stimulate their internal motivation to actively increase their time to improve their labor productivity and achieve their individual goals under the action of incentive behavior, so as to achieve their internal behavioral motivation, which will positively strengthen their decision-making of participating in skills training activities. Meanwhile, there is a significant positive correlation between the number of new professional farmers participating in training and their training willingness. The production and operation skills learned and accepted in the training process have achieved good results in practical activities, which makes them more inclined to participate in skill training.

\subsection{Among the cognitive factors}

The perception of training effect and the perception of training effect are significantly positively correlated with the willingness of new vocational farmers to participate in skill training, which indicates that the more farmers benefit from the existing skill training, the stronger the positive reinforcement effect on their decision-making to participate in training. The perception of teachers' level and hardware level in training institutions and organizations also significantly affect the willingness of new professional farmers to participate in training. The higher the level of teachers and hardware, the more willing farmers are to participate in skills training. There are two possible reasons for the analysis: on the one hand, most of the new vocational farmers themselves are the production and management experts, and the existing knowledge base makes them tend to want to obtain higher-level guidance. On the other hand, it may be because the problems that may be encountered in the application of new technologies and new technologies in the actual production process are more complicated and difficult, so farmers want to get more targeted in-depth guidance. In addition, the perception of training certificate and training cost also has a significant impact on their training willingness. More professional farmers hope to get more free knowledge guidance and corresponding skill certificates in the training process. There is no significant correlation between the perception of training time and the willingness of vocational farmers to participate in skill training.

\section{Countermeasures and suggestions}

The willingness of new occupation farmers to participate in skills training has an important impact on participation, acceptance and practical application of related technologies, and skills. Especially during the COVID-19 period, new occupation farmers can achieve the integration of technology and skills. Based on the above empirical research results, this paper puts forward countermeasures and suggestions to effectively improve the education of new vocational farmers based on the willingness of new vocational farmers to participate in skills training.

5.1 Construction of farmers' vocational education system with the core of enhancing the training willingness of new vocational farmers

In the report of the 19th National Congress of the Communist Party of China, it is pointed out that the implementation of the Rural Revitalization Strategy, the cultivation of new agricultural business entities, and farmers become attractive occupations. Farmers' vocational education is a systematic, long-term and, epochal project. The core lies in how to attract new vocational farmers to actively participate in vocational education and objectively solve the problems of single training form, high repetition rate, and inconsistent supply and demand in the process of farmers'

ISSN: 0010-8189

C CONVERTER 2021

www.converter-magazine.info 
vocational education. Therefore, we should have an objective understanding of the current situation and constraints of the new vocational farmers' training, and strive to build a farmers' vocational education system with the core of improving the new vocational farmers' training willingness. The system is based on improving demand, vocational training menu as the starting point, course certificate as the support of the "Trinity" new vocational farmer education mode. The system integrates relevant education and training resources, establishes the management information database of farmers' occupation education, and develops a new menu material and modular occupation education material. It strives to create a practical, applicable, and occupational mode of vocational education, such as demandoriented, and fast-selling through the network training in COVID-19. At the same time, we should accurately grasp the information teaching characteristics of vocational farmer training. In 2019, the central government official and the State Council Office issued the "Strategic Outline for Digital Rural Development". By 2025, 4G will be popularized and 5G will be innovated and applied in rural areas. Based on the upgrading of information technology and digital technology, it is urgent to establish new technology entrepreneurship and Innovation Service Center for new professional farmers. The center can not only improve the agricultural science and technology information service and promote the cooperation between industry, University, and Research Institute, but also support online and offline integrated teaching and innovative network marketing to solve farmers' technical and sales problems. Especially in COVID-19, information teaching and network marketing are particularly critical.

5.2 Screening vocational education training object training will, innovation farmers vocational education training mode

Based on the above empirical research, $86.21 \%$ of the interviewed farmers are willing to participate in the training, and they have a strong willingness to acquire new knowledge, new technology, and new policies. According to the significance of different factors on the willingness of new vocational farmers to participate in skills training, the training willingness of training objects is screened, and the new mode of "Menu" and "Module" Vocational farmers training is explored to improve the enthusiasm of new vocational farmers to participate in vocational training.

First, we should teach students according to their individual needs and establish an education and training mode with "Students' Will" as the core. In the establishment, implementation, management, and evaluation of vocational training projects, "Students' Will" should be considered as an important link. In the process of vocational training, training standards should be formulated by type, industry, and level. According to the students' different cultural quality, skill needs, practical work, and other practical problems, specific model and menu training courses should be set up, and teaching should be conducted at different levels. In order to meet the requirements of high-quality cultivation of new professional farmers, we should pay special attention to the education of professional ethics, entrepreneurship, and innovation, quality and safety of agricultural products, marketing, financing guarantee, laws and regulations, Internet technology, etc.

Second, it is necessary to develop a diversified, multi-form, multi-level, multi-functional, and open modern agricultural vocational education system in line with the development of modern agriculture. First of all, the system should explore the establishment of research institutes, industrial enterprises, social organizations, and other support policies to jointly establish vocational education groups. We will actively promote the "Double Certificate" system of academic certificates and vocational qualification certificates. Secondly, the system should speed up the development of modern apprenticeship pilot of school-enterprise joint enrollment and joint training, and cultivate new high skilled Agricultural College Students' managers or managers. At the same time, we should speed up the promotion of credit banks, explore various forms of learning achievement identification, accumulation, transformation, and other ways. Thirdly, the system should cultivate leading professional farmers and improve their education level, which can refer to the German dual system. Finally, the system should focus on attracting and training high-quality talents, and establish an incentive mechanism for high-quality talents to return to rural areas. We should give strong support to the new professional farmers who return home to start their own businesses and engage in agricultural management, so as to provide a talent guarantee for the implementation of the Rural Revitalization Strategy.

ISSN: 0010-8189

(C) CONVERTER 2021

www.converter-magazine.info 
Third, it is necessary to implement the path according to people, identify accurately and systematize vocational education. First of all, the departments should perform their duties according to the division of labor and cooperation, carry out classified management and training path design for the national, provincial, municipal, and county-level agricultural leading enterprises, demonstration cooperatives and, farmers, and improve the information files and database of new professional farmers cultivation. Secondly, combined with the industrial background, policy system, personal basic information, and other information, do a good job in SWOT analysis of the training object, identify the training intention of the training object, and teach accurately. Finally, we should constantly strengthen the construction of teaching staff, improve the management system of teacher selection, encourage full-time and parttime teachers to constantly innovate the construction of curriculum system, and improve the quality and effect of teaching. In addition, the focus is to improve the cognitive level of new vocational farmers' participation in training and effectively increase the participation and effectiveness of skill training.

\subsection{Changing government functions to improve the effect of farmers' Vocational Education}

At the present stage, the government bears the main cost of all kinds of farmers' vocational education, but the government's enthusiasm and farmers' indifference form a sharp contrast. The massive investment of funds and the general low efficiency of vocational education seriously affect the effectiveness of training and the performance of funds. Therefore, it is necessary to change the traditional passive and coping training project of new professional farmers and establish a performance evaluation training system which is suitable for the needs of new professional farmers. First of all, at the policy level, we should establish the education security mechanism and training standards of new professional farmers. On the one hand, it is necessary to establish a relatively perfect access mechanism and lifelong education mechanism for new professional farmers. At the same time, quantify the objectives, requirements, and assessment methods of farmers' vocational education and training. On the other hand, we should link the skill training with the acquisition of diploma education certificate, explore the establishment of a new type of professional farmer classification according to the three levels of primary, intermediate and advanced, and clearly include the level of management effectiveness, professional quality, education and training, skill level and other aspects into the evaluation system. Secondly, on the implementation level, we should innovate the training mode of new vocational farmers. Speed up the construction of new occupation farmers' new technology innovation service centers, accelerate the establishment of high-quality "Cloud Classroom", develop APP software and technology products suitable for new occupation farmers, especially in COVID-19, accelerate the popularization and application of new technologies, new varieties and new marketing modes. Finally, on the multi guarantee level of funds, social forces, enterprises, and individuals should be guided to participate in the diversified input mechanism of farmers' vocational education, and various forms of forces should be raised to supplement farmers' vocational education. For example, the backbone leading agricultural enterprises with certain industrial advantages are encouraged to use their own modern agricultural parks to create new vocational farmers training bases and entrepreneurship incubation bases, and the professional cooperatives with certain technical advantages are encouraged to create farmers' field schools.

\section{Acknowledgement}

This work was supported by the Zhejiang Province Philosophy and Social Science Planning Project (Research on the performance evaluation of the cultivation of new professional farmers in the development of modern urban agriculture) under Grant [18NDJC127YB].

\section{References}

[1] Yang Liu, Yang Fan, Meng Shengru. Experience and Enlightenment of cultivating new professional farmers in the United States . Agricultural economic issues, 2019 (06): 137-144.

[2] Li Yi, Gong Ding. Enlightenment of farmers' Vocational Education in Japan and South Korea on the

ISSN: 0010-8189

(C) CONVERTER 2021

www.converter-magazine.info 
cultivation of new vocational farmers in China . World agriculture, 2016 (10): 59-64.

[3] Liu Yiqiao. Enlightenment of German agricultural vocational education on the cultivation of new vocational farmers in China . Agricultural economy, 2018 (04): 64-66.

[4] Yan Tingwu, Zhang Lu, Zhang Junbiao. Exploration and Thinking on the cultivation of new professional farmers -- Based on the survey of Dongxihu District in Wuhan . Journal of Huazhong Agricultural University (Social Science Edition), 2017 (03): 35-41 + 150

[5] Liu Yixi, Hu Chun, Yu Zhenxing, et al. Performance evaluation and analysis of new vocational farmer training in urban agricultural development -- Based on field survey of farmers in scale demonstration cooperatives . Jiangsu agricultural science, 2017,45 (06): 332-337.

[6] Wu Yixiong, Zhou Fangling. Analysis on the agricultural management status and agricultural employment willingness of new professional farmers -- Based on the empirical analysis of hundreds of villages and thousands of people in China . Economic issues, 2017 (05): 89-93

[7] Xu Hui. Cultivation mechanism of new professional farmers under the new normal: a theoretical analysis framework . Agricultural economic issues, 2016,37 (08): 9-15 + 110

[8] Chen Chunxia, Shi Weiping. Research on the formation law of competency of new professional farmers . Research on modern distance education, 2020,32 (06): 69-76

[9] Tian Shuqin, Wang Dongqiang. Comparative study on new vocational education models for vocational farmers based on Polycentric Governance Theory . Education development research, 2020,40 (21): 77 84.

[10] Zhu Qizhen, Hu fangmeng. Several problems on the generation environment of new professional farmers . China's rural economy, 2016 (10): 61-69.

[11] Xu Jinluan. Research on Influencing Factors of training willingness of new vocational farmers in Fujian Province [D]. Fujian Agriculture and Forestry University, 2014.

[12] Xu Qian, Xiao Mengmeng. Research on Influencing Factors of skill training willingness of new vocational farmers -- Taking Qingdao as an example. Journal of Qingdao University of Science and Technology (Social Science Edition), 2020,36 (01): 1-7.

[13] Lin Ning. Analysis on Influencing Factors of vocational farmers' willingness to skill training in Central China in the new era . China Adult Education, 2018 (15): 149-154.

[14] Shen Qiong. Key factors and problems of new professional farmers' sustainable farming . Social scientist, 2020 (09): 15-21.

[15] Shen Qiong, Chen Lu. Influencing factors and hierarchical structure of sustainable operation willingness of new professional farmers -- Based on the survey data of Henan Province . Journal of Hunan Agricultural University Journal (Social Science Edition), 2019, 20 (04): 34-41.

[16] Zhang Wen, Hao Ying, Zhang Guangsheng. Research on Influencing Factors of training willingness of rural backbone labor force -- Empirical Test Based on structural equation model . Agricultural economy, 2013,04:66-68

[17] Li Bao value, Yang Liang Shan, Huang He Xiao, et al. Income effect of new vocational farmer training and its difference analysis . Agricultural technology and economy, 2019 (02): 135-144.

[18] Li Wei, Yang Shiyuan, LAN Dingxiang. The difference between supply and demand of new vocational farmer training and its influence on training effect . Rural economy, 2020 (02): 138-144.

[19] Zhu Qibiao, MI Songhua, Huang Lili, et al. A study on the willingness and influencing factors of new vocational farmers to participate in skill training -- An Empirical Analysis Based on Scale Planting Farmers . Zhejiang Agricultural Journal, 2014,05:1361-1367.

[20] Huang Delin, Chen Yongjie. Study on the willingness and influence mechanism of migrant workers' vocational skills training -- Based on the empirical investigation in Wuhan, Xiamen, and Cangzhou . China soft science, 2014,03:68-75.

[21] Zheng Jun. empirical analysis on Influencing Factors of farmers' willingness to participate in entrepreneurship training -- Based on the survey of Shandong Province. China Rural observation, 2013,05:34-45 + 96 .

[22] Zhang Wen, Hao Ying, Zhang Guangsheng. Research on Influencing Factors of training willingness of 
Volume 2021, No. 5

rural backbone labor force -- Empirical Test Based on structural equation model . Agricultural economy, 2013,04:66-68.

[23] Fu Xuemei, Zhuang Tianhui. Chengdu new vocational farmer training mode and its influencing factors . Guizhou Agricultural Science, 2016,44 (01): 171-176 + 181 . 